\title{
Essential Dynamics for Developing Models for Control of Connected and Automated Electrified Vehicles: Part A - Powertrain
}

Sadra Hemmati ( $\sim$ shemmati@mtu.edu )

Michigan Tech https://orcid.org/0000-0003-0793-4677

Rajeshwar yadav

GKN Driveline

Kaushik Surresh

Michigan Technological University

Darrell Robinette

Michigan Technological University

Mahdi Shahbakhti

University of Alberta

\section{Research Article}

Keywords: Connected and Automated Vehicles, Automotive Control, Energy Efficiency

Posted Date: May 18th, 2021

DOI: https://doi.org/10.21203/rs.3.rs-536651/v1

License: (c) (1) This work is licensed under a Creative Commons Attribution 4.0 International License.

Read Full License 


\section{ESSENTIAL DYNAMICS FOR DEVELOPING MODELS FOR CONTROL OF CONNECTED AND AUTOMATED ELECTRIFIED VEHICLES: PART A - POWERTRAIN}

\author{
Sadra Hemmati \\ Michigan Technological University \\ Houghton, Michigan 49931 \\ Email: shemmati@mtu.edu
}

\author{
Rajeshwar Yadav \\ GKN Driveline \\ Email: ryadav1@mtu.edu
}

\author{
Kaushik Surresh \\ Michigan Technological University \\ Email: ksurresh@mtu.edu
}

\author{
Darrell Robinette \\ Michigan Technological University \\ Email: dlrobine@mtu.edu
}

\author{
Mahdi Shahbakhti \\ University of Alberta \\ Edmonton, Alberta, Canada \\ Email: mahdi@ualberta.ca
}

\section{ABSTRACT}

Connected and Automated Vehicles (CAV) technology presents significant opportunities for energy saving in the transportation sector. CAV technology forecasts vehicle and powertrain power needs under various terrain, ambient, and traffic conditions. Even though the CAV technology is applicable to both conventional and electrified powertrains, the energy saving opportunities are more apparent when the CAVs are Hybrid Electric Vehicles (HEVs). This is because of the flexibility in the vehicle powertrain and possibility of choosing optimum powertrain modes based on the predicted traction power needs. In this paper, the powertrain dynamics essential for developing powertrain controllers for a class of connected HEVs is presented. To this end, control-oriented powertrain dynamic models for a test vehicle consisting of full electric, hybrid, and conventional engine operating modes are developed. The resulting powertrain model can forecast vehicle traction torque and energy consumption for the specified prediction horizon of the test vehicle. The model considers different operating modes and associated energy penalty terms for mode switching. Thus, the vehicle controller can determine the optimum powertrain mode, torque, and speed for forecasted vehicle operation via utilizing connectivity data. The powertrain model is validated against the experimental data and shows prediction error of less than $5 \%$ for predicting vehicle energy consumption.

\section{Introduction}

With increased penetration of electrification and connectivity technologies in the market, the potential for intelligent and energy-efficient transportation becomes more salient [1]. According to the U.S. Energy Information Administration (EIA) 2020 outlook for the transportation industry, light-duty hybrid electric vehicle sales in the U.S. are predicted to increase $3.1 \%$ per year, rising to a projected sales of more than 900,000 vehicles in 2050, while battery electric vehicle (BEV) sales will increase by $6 \%$ per year on average [2]. $\mathrm{HEV} / \mathrm{BEV}$ powertrain is a 
complex system consisting of numerous sub-systems. To ensure good fuel economy and drivability, it is imperative to model and characterize the dynamic interactions among the components. To establish and understand these interactions, physical prototyping and testing prove to be too expensive [3], whereas modeling and simulation is considered cost-effective and time-saving for modeling and control of connected electrified powertrains [4]. Connectivity facilitates forecasting future tractive and thermal loads and power demands to the vehicle. This can be utilized for intelligent control and energy saving [1]. Even though CAV information is helpful for the energy-efficient operation of conventional vehicles, EVs, and HEVs, the energy saving opportunities are more apparent when the CAVs are HEV due to flexibility in selecting the vehicle powertrain operating modes. In this paper, the powertrain dynamics that should be modeled for developing powertrain controller for connected vehicles is presented, with emphasis on connected HEVs (CHEVs).

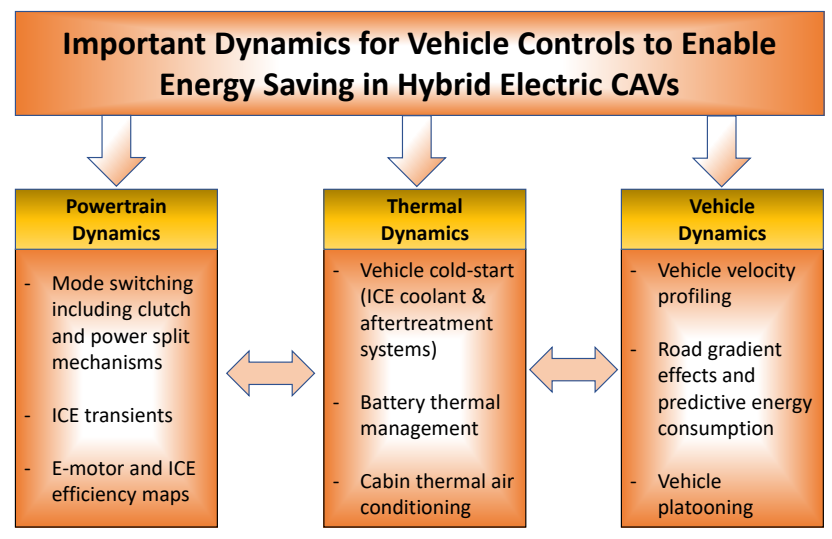

FIGURE 1: Essential dynamics affecting control of connected hybrid electric vehicles (CHEVs)

The overview of the dynamics essential for energy-efficient CHEV controls is provided in Fig.1. These dynamics include powertrain dynamics, thermal dynamics, and vehicle dynamics. As shown in Fig.1, these three dynamics are not decoupled: each one has implications on the other two. For instance, the operation of engine during cold-start includes thermal dynamics and may also include inefficient powertrain operation due to incomplete engine combustion. Another example includes vehicle ve- locity profiling in CAVs' control that highly depends on powertrain capability and vehicle dynamics, but also affects cabin thermal management due to the effect of vehicle speed on convective heat transfer between ambient and the cabin [29]. The three areas in Fig.1 include a large number of important dynamics for CAV control. This paper (part A) focuses on powertrain dynamics, while our subsequent paper (part B) focuses on thermal dynamics and vehicle dynamics. In particular, part $\mathrm{A}$ is centered on the dynamics essential for developing control-oriented and computationally-efficient powertrain models, and covers mode switching dynamics (clutch and power split mechanisms), internal combustion engine (ICE) transient dynamics, and e-motor energy conversion efficiency.

Vehicle powertrain models can be classified as steady state, quasi-static, and dynamic. Steady state models (e.g., Autonomie [40] and ADVISOR [36]) and quasi-static models (e.g., powertrain system analysis toolkit (PSAT) [37]) typically use mapbased models of vehicle sub-systems. Their main advantage is quick computation time; however, since they do not consider system dynamics, they become inaccurate for transient operations. Dynamic modeling approach typically uses dynamic physicsbased models for vehicle sub-components, to ensure better accuracy in transient conditions, compared to static/ quasi-static models. Vehicle models are further classified as forward-looking (driver driven) or backward-looking (vehicle driven) models, depending on the direction of power flow calculation [38]. The calculation proceeds in the forward direction of powertrain power flow using transmitted torque and reflected torque and driver needs for speed tracking. On the other hand, backward models initiates from the traction force request at the wheels to the primary energy sources and is generally made of quasi-static models. ADVISOR is one example of backward model [36].

A list of prior CAV studies, including powertrain models, is presented in Fig.2. Three classes of connected vehicles, grouped by powertrain type, can be seen in Fig. 2:

i) Conventional engine-based connected vehicles (ECVs): In [10], the authors implemented Eco-Approach, Eco-Departure, and Eco-Cruise control algorithms on a 2018 Cadillac CT6 testbed, in a high-fidelity dynamic model, and reported that the scenario in which driver was informed of the preview data had an $11 \%$ fuel saving compared the baseline. In [11], the authors 


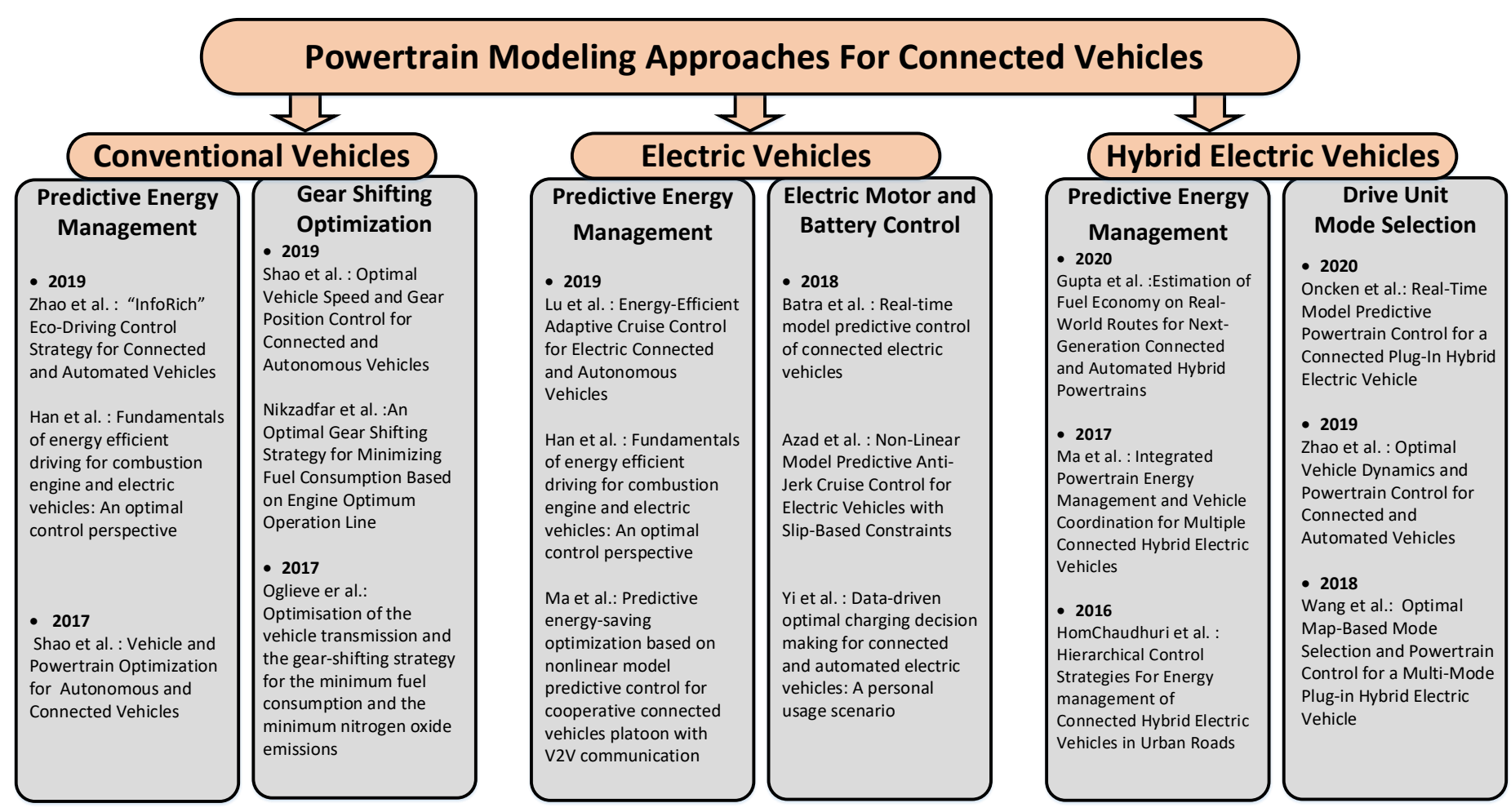

FIGURE 2: Prior studies including modeling powertrain for control of CAVs [13-29].

utilized a dynamic model and implemented bang-singular-bang optimal control to make decisions on the periods of maximal acceleration, maximal braking, coasting, and constant speed cruising for an engine-based connected vehicle, while provided with the CAV data. The authors reported up to $35 \%$ fuel energy saving using their proposed controller. In [12], the authors described a rule-based powertrain controller using CAV information for a conventional vehicle that resulted in $17 \%$ energy saving compared to the baseline non-CAV operation. In addition, for an $\mathrm{ECV}$, the transmission gear position can be optimized to adapt to anticipated future vehicle speed and power demand. In [13], the authors proposed a control strategy to optimize vehicle speed and gear position simultaneously for an ECV, while considering both fuel efficiency and drivability. The results showed a $16 \%$ fuel benefits compared to a baseline. In [14], an optimal gearshifting strategy is presented to minimize fuel consumption and number of gear shifts in the new European driving cycle (NEDC). The results show a $4 \%$ reduction in fuel consumption using the CAV information compared with the baseline. The authors only considered using a quasi-static brake-specific fuel consumption (BSFC) map-based engine model without engine dynamic transients. In [15], the authors proposed a computationally efficient model for evaluating the fuel consumption during the NEDC for gear selection and energy consumption. The optimization leads to a reduction of $7.5 \%$ in BSFC.

ii) Hybrid electric connected vehicles (CHEVs): When the vehicle platform is $\mathrm{HEV}$, the vehicle controllers will be more complex, but the controllers have more opportunities to save energy by using the CAV information. In [22], the authors assess real-world fuel economy of CHEVs with advanced cylinder deactivation and $48 \mathrm{~V}$ mild hybridization, in the presence of some variability induced by route characteristics, traffic condition, and driver behavior. For the evaluated route, the authors reported a $15 \%$ to $19 \%$ reduction in fuel consumption, compared to a baseline vehicle, without cylinder deactivation and CAV information. In [23], the powertrain dynamics is modeled using physics-based ODEs and used for the purpose of an integrated dynamic programming optimization of multiple CHEVs' oper- 
ation, to achieve group-level energy efficiency. In [24], the authors present a fuel efficient and hierarchical Model Predictive Control (MPC) strategy based on Equivalent Consumption Minimization strategy (ECMS) for a group of CHEVs in urban road conditions, and report an overall $12 \%$ energy consumption reduction compared with the baseline. In [26], the authors presented a two-level control architecture for a CHEV to optimize the vehicle speed profile and powertrain efficiency simultaneously. The powertrain is modeled in Vehicle-Engine SIMulation (VESIM) environment, whereas VISSIM is also used for traffic modeling. Improvements of fuel efficiency compared with the baseline scenarios, under different traffic conditions, range from $7 \%$ to $40 \%$. In [27], the authors present an optimal map-based mode selection and powertrain control for a multi-mode CHEV. The best mode map and the best operation maps for powertrain components are generated using ECMS to minimize equivalent fuel cost at each operating point. In [28], the authors studied a drive mode optimization problem on a Chevrolet Volt to enable optimal drive modes for fuel minimization based on trip information, using a multidimensional correlation powertrain model.

iii) Fully-electric connected vehicles (CEVs): In [17], the authors developed a map-based EV powertrain model to explore the effects of different velocity profiling methods on energy efficiency of simulated CEVs in a single-lane traffic stream. In [11], the authors used a simplified EV model to explore the effect of different control strategies on the energy consumption. In [18], the authors simulate rear wheel CEVs driven by two permanent magnet synchronous in-wheel motors (PMSM), and reported energy savings up to $6 \%$ for Urban Dynamometer Driving Schedule (UDDS) obtained through proposed control algorithms. In [19], a look-ahead model predictive controller (LA-MPC) is designed that calculates the required motor torque demand to meet the dual objectives of increased traction, and anti-jerk control of a CEV. The authors developed a high-fidelity powertrain model in MapleSim software, and then reduced the order of the model for real-time control. In [20], the authors developed a nonlinear model predictive (NMPC) low-jerk cruise controller for an electric vehicle. A high-fidelity longitudinal dynamics model was developed for the test vehicle. The performance of the controller on the jerk index of the vehicle was assessed in a HIL simulation using the high-fidelity vehicle model while following a US06 driving cycle. In [21], the authors utilized a correlation-based powertrain model to perform a dynamic programming optimization for charging decisions of a CEV.

This paper builds upon our extensive study for CHEV modeling and control as part of the U.S Department of Energy ARPA-e NEXTCAR program. The main new contributions of this work are: $i$ ) presenting the essential dynamics, including the engine transients and operating mode switching energy penalties, needed for computationally efficient and real-time control-oriented powertrain modeling of a CHEV, ii) systematic low-order modeling and experimental validation of powertrain dynamics suitable for fast execution with low computational cost, iii) vehicle experimentation and characterization at the component-level and system-level for charge-depleting and charge-sustaining operating modes, and $i v$ ) assessment of energy distribution of the test vehicle by sub-component in the chargedepleting operation mode for three U.S drive cycles. It is noteworthy that in none of the studies mentioned previously, the authors explicitly stated that they have used engine fuel penalty terms in powertrain modeling.

The structure of this paper is as follows: in Section 2, the vehicle setup, instrumented sensor suites, and the CAN-based data acquisition procedure is discussed. In Section 3, the powertrain dynamics and the experimental model validation of various powertrain sub-systems are discussed. After each sub-system model description, validation of that sub-system for the US06 drive cycle is followed. Included in this Section are engine transient dynamic model, engine fuel penalty terms, mode switching energy penalty terms, modeling of e-motor, drive unit, and Li-ion battery. Section 4 investigates: $i$ ) interdependence of the powertrain operating mode and the efficiency $i$ ) energy distribution analysis of the test vehicle at the sub-component level, and iii) the effect of hysteresis on the powertrain dynamics and efficiency. Section 5 summarizes the findings from this paper.

\section{Vehicle Test Setup}

The test vehicle of this study is a Chevy Volt II generation, a light-duty plug-in HEV with two motor-generator units and an engine for propulsion. The test vehicle could be run in pure electric, hybrid electric, and conventional engine operations. This allows to determine vehicle powertrain dynamics for varying elec- 


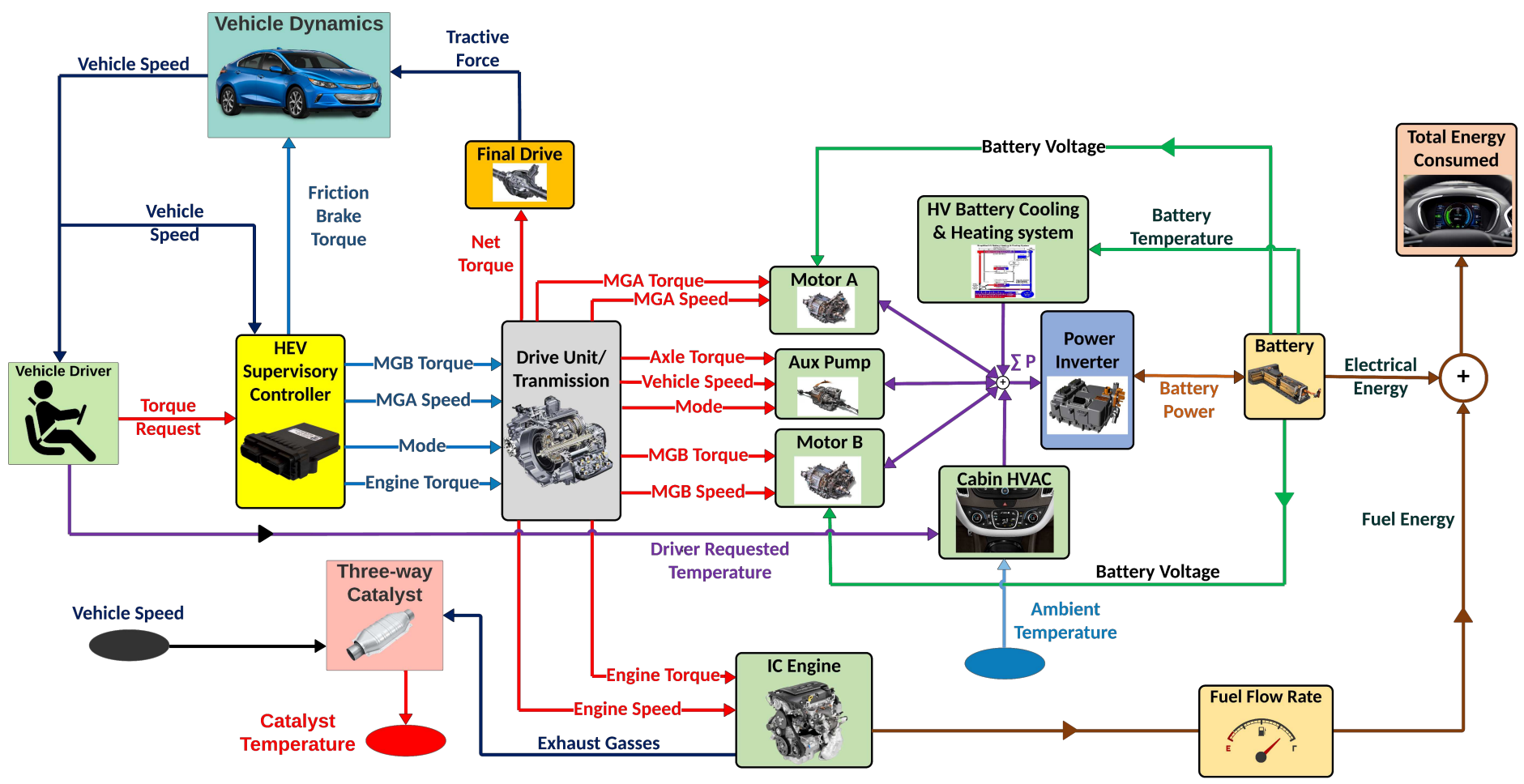

FIGURE 3: Overview of the powertrain and vehicle dynamics model for the test vehicle in this study.

trification uses for 0 to $100 \%$ electric operation. The maximum powers of the engine and two motor-generators are 75, 87, and $48 \mathrm{~kW}$, respectively. The battery capacity is $18.4 \mathrm{kWh}$, providing energy for $85 \mathrm{~km}$ all-electric range. The extended range of the test vehicle is $680 \mathrm{~km}$. The test vehicle was connected to a datalogger so that the controller area network (CAN) bus communications (two channels of CAN bus for fast and ultra-fast communication of electronic control units (ECUs) to the components' nodes) could be stored for analysis. In addition to the signals available from the CAN bus, the test vehicle was instrumented with a suite of sensors including accelerometers, gyroscopes, an anemometer, GPS, radar, and Lidar, as shown in Fig. 4(a). The data logger setup utilized MicroAutoBox dSPACE ${ }^{\circledR}$ embedded PC, placed at the trunk of the test vehicle, as shown in Fig. 4(b).

The vehicle was tested at Michigan Tech's Advanced Power Systems Research Center (APSRC). In addition, extensive vehicle test data was provided by the Argonne National laboratory (ANL) through chassis dynamometer tests for different drive cycles.

\section{Powertrain Dynamics and Modeling}

In this Section, the major powertrain dynamics for control of a CHEV are presented and modeled for the test vehicle in this work. Fig. 3 shows the overall structure of the vehicle powertrain model and its dependencies on the vehicle dynamics, driver torque request, and HEV supervisory controller. A control-oriented model is developed for the vehicle powertrain to assist CHEV model-based real-time controllers. The model uses dynamic equations and experimental map data. In the following, modeling major powertrain dynamics is discussed.

\subsection{Internal Combustion Engine Model}

A dynamic model of a 1.5 liter 4-cylinder naturally aspirated DI SI engine is developed based on the principles outlined in [32-34] to predict the engine torque, speed, and instantaneous fuel consumption and fuel penalty terms for moving from one engine speed and torque condition to another operating point during transient engine operation. The model schematic is shown in Fig. 5. The engine model includes intake air flow dynamics, rotational dynamics, torque generation, and exhaust gas recircu- 
(a)

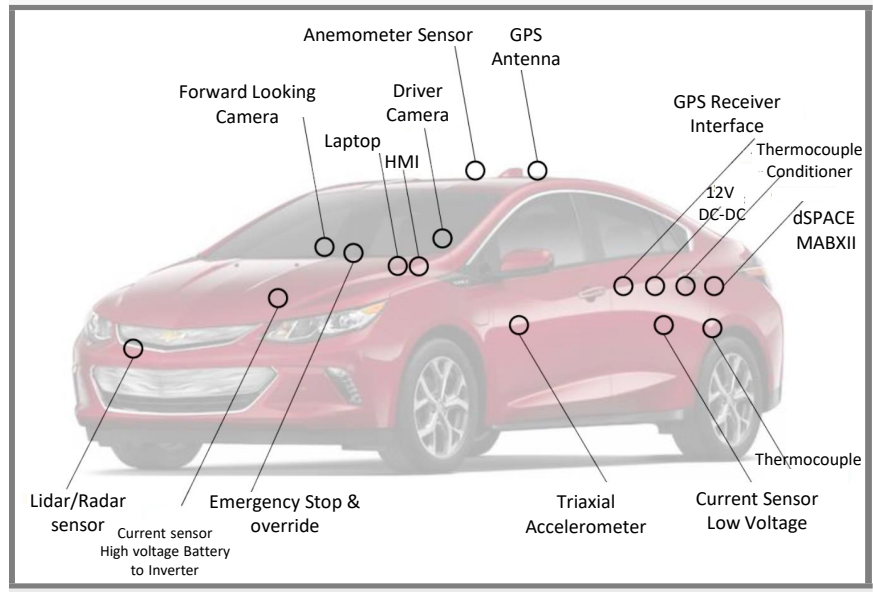

(b)

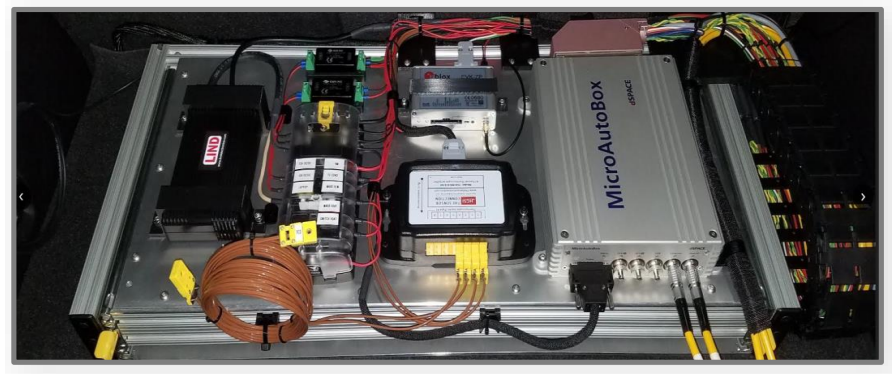

FIGURE 4: Vehicle test setup, including: (a) the suite of various instrumented sensors such as accelerometers and gyroscopes, and (b) data acquisition setup utilizing MicroAutoBox dSPACE ${ }^{\circledR}$ embedded PC.

lation (EGR) flow dynamics. As shown in Fig. 5, the engine controller commands the throttle valve opening angle, spark timing, fuel injection amount and timing, and EGR percentage based on the requested torque. At the same time, the supply intake airflow rate and fuel flow rate are adjusted by the ECU to achieve the desired air-fuel ratio. Intake air-flow enters the intake manifold, and mixes with EGR flow before entering into cylinders. This air-EGR mixture enters the engine cylinder during the intake process and the amount of fuel injected is determined in the DI fuel injection sub-system. The ECU considers extra fuel (i.e., fuel penalty) based on engine coolant and three-way catalyst (TWC) temperatures. This is to ensure air-fuel mixture is combustible during cold start and also minimize TWC light-off time via catalyst heating to minimize vehicle tailpipe emissions. Engine torque is determined as a function of spark timing, AFR, in-cylinder air mass flow rate, and engine speed. Finally, the engine speed is determined in the rotational dynamics sub-system.
Engine speed and torque are the outputs of the engine model being fed to the drive unit/ transmission sub-system. From a control perspective, besides satisfying the drivetrain dynamics to control the longitudinal speed or acceleration of the vehicle, engine control system objectives of the ECU include: $i$ ) To maintain air-fuel ratio at a desired value, ii) To maintain engine-out emission below required threshold, and iii) To heat up TWC during cold start by adjusting spark timing, engine speed, AFR, and fuel injection amount and timing [33,34]. The governing equations to represent important engine dynamics are summarized as follow.

$$
\begin{gathered}
\dot{X}_{1}=f_{1}\left(X_{1}, U_{1}\right) \\
X_{1}=\left[\dot{m}_{a t}, \dot{m}_{E G R}, \dot{m}_{a c}, N_{\text {eng }}, E G R, \eta_{v o l}, P_{\text {man }}, T_{b r}, \lambda, T_{\text {ind }}, T_{f}, \dot{m}_{f}, T_{m a n}\right]^{\top} \\
=\left[x_{1}, x_{2}, x_{3}, x_{4}, x_{5}, x_{6}, x_{7}, x_{8}, x_{9}, x_{10}, x_{11}, x_{12}, x_{13}\right]^{\top} \\
U_{1}=\left[\theta, S A, E G R_{v, p}, V T\right]^{\top}=\left[u_{1}, u_{2}, u_{3}, u_{4}\right]^{\top} \\
x_{1}(t)=f_{3}\left(u_{1}, u_{2}, u_{4}\right)=k_{1} \cdot A\left(u_{1}\right) \cdot x_{7} \cdot \sqrt{k_{2} \cdot\left(1-\left(\frac{x_{7}}{P_{0}}\right)^{\left(\frac{\gamma-1}{\gamma}\right)}\right.} \\
x_{2}(t)=f_{4}\left(u_{1}, u_{3}, u_{4}\right) \\
x_{3}(t)=\frac{x_{6} \cdot x_{4} \cdot \rho_{a, m} \cdot V_{\text {man }}}{2}=x_{1}+x_{2}-\frac{x_{7} \cdot V_{\text {man }}}{R \cdot x_{13}} \\
\omega_{\text {eng }}=\frac{2 \cdot \pi}{60} \cdot x_{4} \\
x_{4}(t)=\frac{60}{2 . \pi} \cdot \int_{t_{0}}^{t} \frac{x_{10}+x_{11}-T_{\text {Load }}}{J_{\text {eff }}} d t \\
x_{5}(t)=\frac{x_{2}}{x_{1}+x_{2}} \\
x_{6}(t)=k_{3}+k_{4} \cdot x_{4}+k_{5} \cdot x_{4}{ }^{3}+k_{6} \cdot x_{7} \\
x_{7}(t)=f_{5}\left(u_{1}, u_{4}\right) \\
x_{11}(t)=a_{0} \cdot \omega_{\text {eng }}^{2}+a_{1} \cdot \omega_{\text {eng }}+a_{2}+b_{0} \cdot \omega_{\text {eng }} \cdot x_{7}+b_{1} \cdot x_{7} \\
x_{12}(t)=\frac{x_{1}}{x_{9} \cdot L_{t h}} \\
x_{10}(t)=f_{6}\left(x_{6}, x_{7}, u_{1}, u_{4}\right) \\
x_{9}(t)=\frac{x_{11}}{x_{1}+x_{2}-x_{3}} \\
x_{3}\left(x_{3}, x_{4}, x_{9}, u_{2}\right)
\end{gathered}
$$

Where, $T_{\text {ind }}$ is the engine indicated torque, $T_{\text {load }}$ is the ex- 


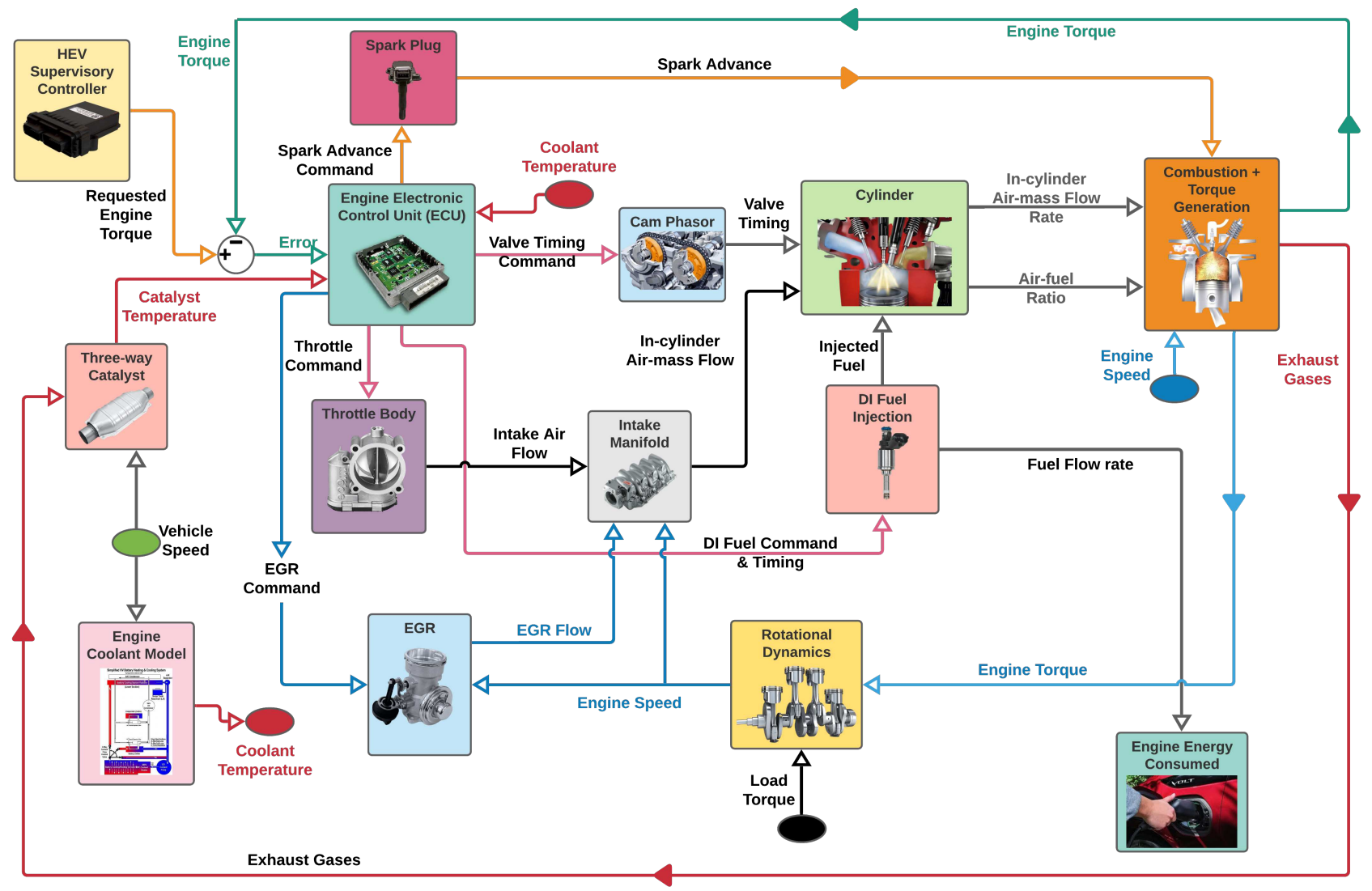

FIGURE 5: The developed engine dynamic model in this study.

ternal load torque on the crankshaft, $T_{f}$ represents the pumping and friction losses in the engine and $J_{\text {eff }}$ is the effective rotational moment of inertia for the engine crankshaft, $S A$ is spark advance, $E G R_{v, p}$ is the valve position for EGR, $V T$ is the valve timing command from the ECU, $H_{u}$ is the heating value of fuel, $\eta_{i}$ is the indicated thermal efficiency. $\dot{m}_{f}$ represents the fuel mass flow rate into the cylinders.

$L_{t h}$ is the stoichiometric air/fuel mass ratio for gasoline fuel and $\lambda$ is the air/fuel equivalence ratio. The term $T_{f}$ represents the hydrodynamic and pumping friction losses represented in terms of a loss torque. Hydrodynamic or fluid-film friction is the principal component of mechanical friction losses in the engine [34].

$a_{0}, a_{1}, a_{2}, b_{0}$, and $b_{1}$ are parameters that are determined by experimental engine testing to calculate the friction torque. $\theta$ is the throttle angle, $A\left(u_{1}\right)=A(\theta)=A_{T}$ is the throttle angledependent area, $\dot{m}_{a t}$ is the throttle air flow rate, $\dot{m}_{E G R}$ is the EGR flow rate, $\dot{m}_{a c}$ is the in-cylinder air flow rate, $V_{\text {man }}$ is the intake manifold volume, $T_{\operatorname{man}}$ is the manifold temperature, $R_{u}$ is the universal gas constant, $\eta_{v o l}$ is the volumetric efficiency, $\rho_{a, m}$ is the air density, $N$ is the engine speed, $k_{1}=\frac{C_{D} \cdot \gamma^{0.5}}{\sqrt{R \cdot T_{0}}}, k_{2}=\frac{2 \times \gamma}{\gamma-1}$, and $K_{3}, K_{4}, K_{5}$, and $K_{6}$ are regression constants. $C_{D}$ is the discharge coefficient of valves, $P_{0}$ and $T_{0}$ are the ambient pressure and temperature values, respectively, $\omega_{\text {eng }}$ is the angular speed of engine crankshaft in rad/sec, $T_{b r}$ is the engine brake troque (N.m), $p_{r}$ is ratio of intake manifold pressure to ambient pressure, and $\gamma$ is specific heat ratio. Volumetric efficiency $\left(\eta_{v o l}\right)$ depends on the manifold pressure and the engine speed, and is estimated using regression of experimental engine data.

3.1.1 Engine Startup Fuel Penalty Engine and three-way catalyst (TWC) thermal conditions and temperatures play important roles in ECU strategies to adjust fuel injections. These affect the engine fuel flow rate and should be considered 
in the engine dynamic modeling to improve vehicle fuel consumption prediction. Three categories of fuel penalty, depending on the engine startup status are considered in this work, shown in Fig. 6: i) Engine cold-start fuel penalty: Engine cold-start leads to increased fuel consumption because of the need to inject more fuel since low cylinder wall temperature and cold air result in poor combustibility of injected fuel [43]. In addition, high viscosity of the lubricant between piston and the liner interface results in increased friction losses [43], ii) TWC light-off fuel penalty: ECU commands to run the engine at high speed to quickly heat up TWC which leads to higher fuel consumption. For the TWC temperature below $300^{\circ} \mathrm{C}$, the TWC conversion efficiency is less than $50 \%$, leading to high $\mathrm{CO}, \mathrm{HC}$, and NOx tailpipe emissions [33], and iii) Cranking fuel penalty: Cranking happens between the time of start of the engine crankshaft rotation from the rest position until the engine achieves stable idling speed (e.g., 600-700 RPM). During the cranking transient engine operation, ECU commands appropriate fuel injections to initiate first engine combustion cycles until the engine reaches sustainable combustion status.

These three fuel penalties were quantified by analysing the test vehicle data under cold and normal conditions. Finally, these three penalties were determined based on engine coolant temperature (e.g., $\mathrm{T}_{\text {coolant }}<0^{\circ} \mathrm{C}$ ) and TWC temperature (e.g., $\mathrm{T}_{T W C}<300^{\circ} \mathrm{C}$ ). The results, shown in Fig. 6-(a), indicate that the coolant light-off fuel penalty is very substantial; thus, CAV controller should minimize the need for TWC heating by monitoring the TWC temperature. The second significant fuel penalty is the engine col-start and finally, the cranking fuel penalty is the least significant. These penalty factors need to be taken into account in the CAV controller.

3.1.2 Model Validation The engine model was implemented in MATLAB/ Simulink ${ }^{\circledR}$ and was experimentally validated with extensive vehicle test data. Validation of engine torque, fuel flow, and air flow are shown in Fig. 7 for US06 drive cycle. The validation results show the developed dynamic engine model can predict engine torque and instantaneous fuel consumption with RMSE of 4.7 N.m and $0.7 \mathrm{~g} / \mathrm{sec}$, respectively, during the transient engine operation.

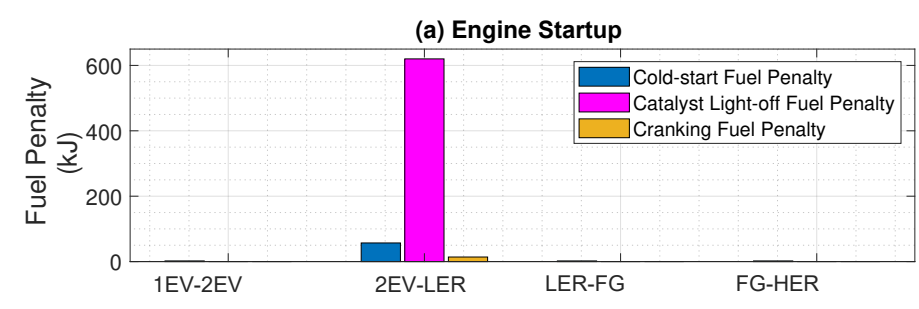

(b) Auxilliary pump

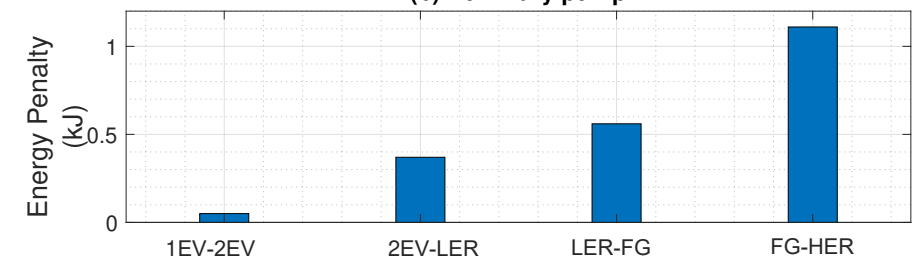

FIGURE 6: Mode switching fuel or energy penalty due to (a) engine startup, and (b) need to apply the transmission unit auxiliary pump.

(a)

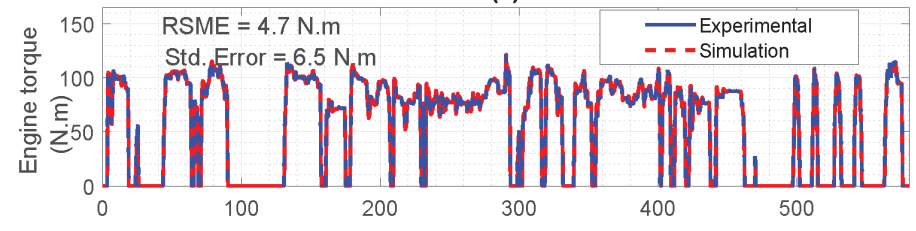

(b)

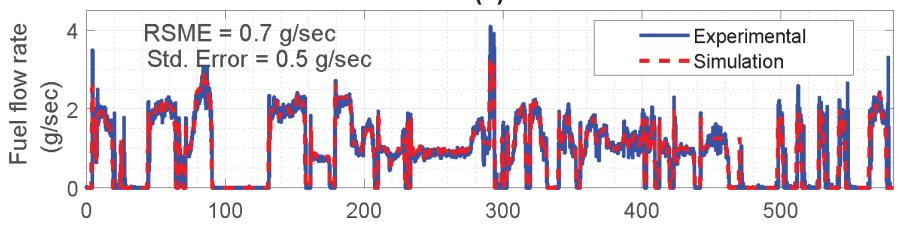

(c)

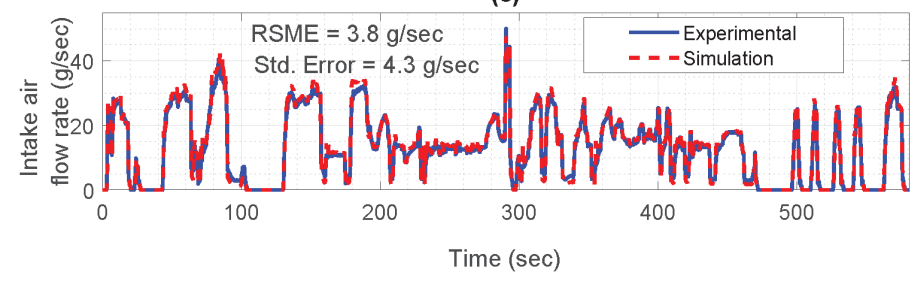

FIGURE 7: Validation of engine dynamic model for US06 drive cycle: (a) engine torque, (b) fuel flow rate, and (c) intake air flow rate.

\subsubsection{Fuel Penalty Mapping for Engine Transients}

Depending on the HEV operating mode, the engine operation could involve substantial engine transients. Fig. 8 shows the engine operating points for three standard US drive cycles. These cover a large span of engine speed and torque operating conditions, as can be seen in Fig. 8. The CAV controller needs to know the fuel penalty associated with any commanded engine 
transient that is determined by the commanded powertrain operating mode, powertrain components engaged, vehicle dynamics, road load, and driver torque demand. To this end, the experimentally validated model is used to carry-out transient fuel penalty analysis. This was done by giving various step torque commands at various engine speeds (e.g., torque step from 50 $\mathrm{N}$ to $60 \mathrm{~N}$ at $2000 \mathrm{RPM}$ ) and capturing the engine torque response and ECU commanded control actions such as injected fuel amount and throttle position. Typically it takes several engine cycles to go from one operating point to another. The associated fuel injections during this transition is counted as fuel penalty due to a transient. Many such simulations were conducted to generate a fuel penalty lookup map for the HEV energy management controller. Fig. 9 shows the transient fuel penalty map for average change in speed ( $\Delta$ Engine Speed) and torque ( $\Delta$ Engine Torque). This map has been used in the test vehicle's CHEV controller [25] to determine fuel penalties associated with engine transients. This makes the model predict transient fuel penalties in a simple, computationally efficient fashion and enables the real-time vehicle energy management controller to optimally select the engine operating points and powertrain modes and minimize engine transients.

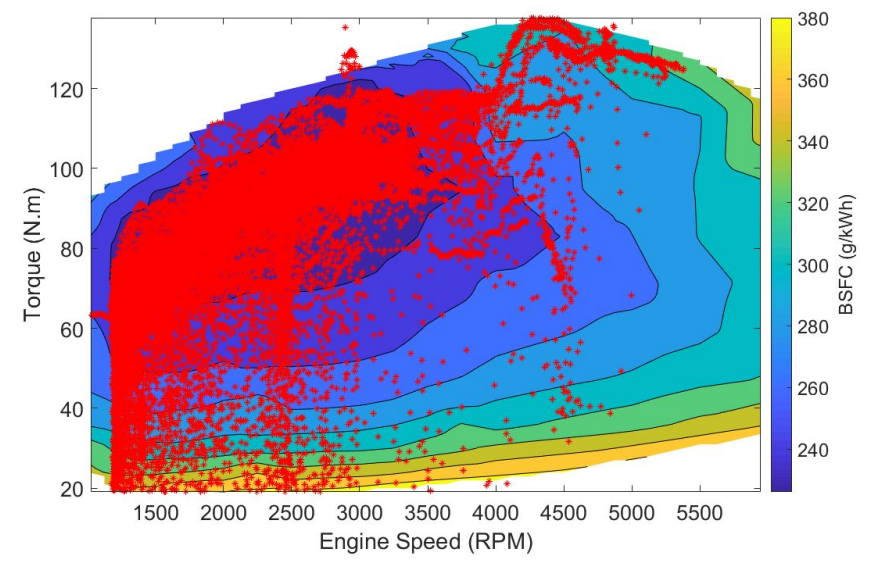

FIGURE 8: Operating points of the engine on the BSFC map for vehicle operation during various drive cycles including US06, UDDS, and HWFET.

\subsection{Electric Motor-Generator Model}

The test vehicle has two permanent magnet electric motorgenerators (MG) for propulsion and regeneration, denoted by

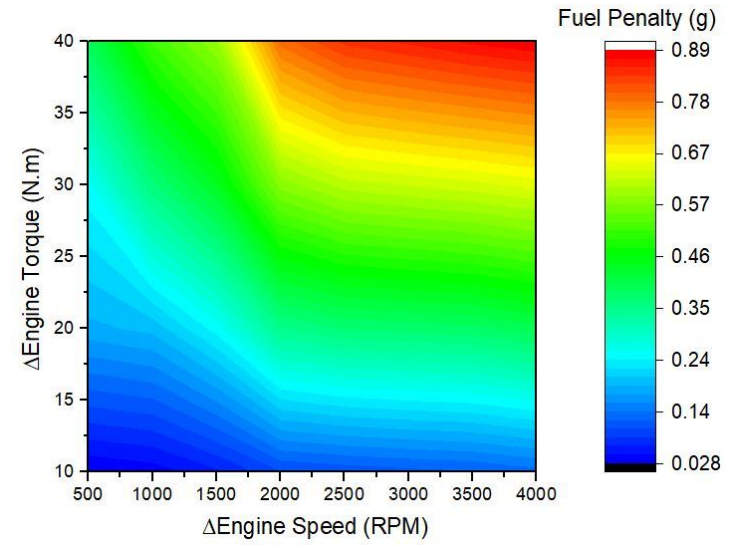

FIGURE 9: Generated average fuel penalty map for engine transients based on changes $(\Delta)$ in engine torque and speed. This map can be utilized by CHEV controller for commanding engine torque and speed based on forecasted power needs.

MGA and MGB as previously shown in Fig. 3. A MG Simulink ${ }^{\circledR}$ model of MGA and MGB was developed by considering system dynamics through Equations (18) to (29) along with the experimental efficiency maps for each MG. Inputs to the model are motor speed and torque, as shown in Fig. 3, and the output is the battery power request. Different efficiency terms (mechanical, electrical, and power electronics) are considered to determine energy conversion at each time instance that constitutes a state variable for each MG. In addition to these, armature amperage and voltage, and back electromotive force of each of the MGs are considered as states of the dynamics system. The methodology described in [8] was used for the mathematical modeling of MGs.

$$
\begin{gathered}
\dot{X}=f(X, U) \\
X=\left[K_{P M}, \eta_{\text {elec }}, \eta_{T P I M}, i_{a}, e_{a}, V_{a}\right]^{\top} \\
=\left[x_{1}, x_{2}, x_{3}, x_{4}, x_{5}, x_{6}\right]^{\top} \\
U=\left[T_{M G}, \omega_{M G}\right]^{\top}=\left[u_{1}, u_{2}\right]^{\top} \\
Y=\left[P_{\text {Batt }}, \eta_{\text {mec }}\right]^{\top}=\left[y_{1}, y_{2}\right]^{\top} \\
x_{1}(t)=j\left(u_{1}, u_{2}\right) \\
x_{2}(t)=g\left(u_{1}, u_{2}\right) \\
x_{3}(t)=h\left(u_{1}, u_{2}\right) \\
x_{4}(t)=\frac{u_{1}}{K_{P M}}
\end{gathered}
$$




$$
\begin{gathered}
x_{5}(t)=K_{P M} \cdot u_{2} \\
x_{6}(t)=x_{5}+x_{4} \cdot R_{a} \\
y_{1}(t)=\frac{u_{1} \cdot u_{2} \cdot x_{2} \cdot x_{3}}{x_{1}} \\
y_{2}(t)=\frac{u_{1} \cdot u_{2}}{x_{4} \cdot x_{6}}
\end{gathered}
$$

Where, $T_{M G}$ is the torque of the MG (N.m), $\omega_{M G}$ is the angular velocity of the MG ( $\mathrm{rad} / \mathrm{sec}), \eta_{\text {mec }}$ is the mechanical efficiency of the MG, $\eta_{\text {elec }}$ is the electrical efficiency of the MG, $\eta_{T P I M}$ is the efficiency of the power-electronics module, $i_{a}$ is the current through the electrical side (A), $e_{a}$ is the back electromotive force of the motor $(\mathrm{V}), V_{a}$ is the terminal voltage of the motor $(\mathrm{V})$, and $R_{a}$ is the armature resistance $(\Omega)$.

The experimental validation of MGA and MGB for a chargedepleting US06 drive cycle is shown in Fig.10. The validation results show that the electric MG model can predict the battery power demand by RMSE of less than $2 \mathrm{~kW}$ including motor traction and regeneration operating conditions.

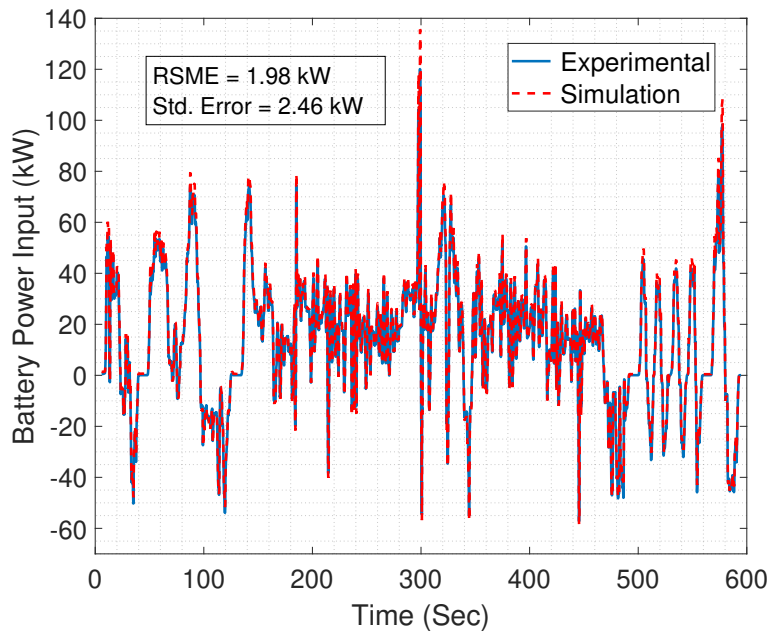

FIGURE 10: Motor generator model experimental validation for operation under US06 drive cycle during charge depletion.

3.2.1 Li-ion Battery Model Chevy Volt includes a 18.4 kW.hr Li-ion battery, with a maximum power of $120 \mathrm{~kW}$ and peak capacity of 52 A.h to supply the electrical energy for propulsion and auxiliary units. This $183 \mathrm{~kg}$ battery pack is arranged in two parallel branches, each containing 96 cells in se- ries, resulting in improved packaging efficiency and energy density [41]. The cooling for the battery pack is done via liquid cooling, while heating is done by using a $2.4 \mathrm{~kW}$ electrical heater. An integrated electrical-thermal Simulink ${ }^{\circledR}$ model was developed using the battery parameters. The model utilizes the " $2 \mathrm{RC}$ " method [42] for voltage and current trace replication. In this method, the electrical dynamics of the battery pack is modeled by using two circuits, one modeling the long-term, and the other modeling the short-term dynamics of the battery pack. As shown in Fig.11, a separate thermal sub-model provides the electrical sub-model with the battery pack temperature information that highly affects the battery electrical dynamics.

The battery electrical model developed in this work is summarized by following equations:

$$
\begin{gathered}
\dot{X}_{2}=f_{2}\left(X_{2}, U_{2}\right) \\
X_{2}=\left[V_{C T S}, V_{C T L}, C_{T S}, C_{T L}, R_{S}, R_{T S}, R_{C S}\right]^{\top} \\
=\left[x_{1}, x_{2}, x_{3}, x_{4}, x_{5}, x_{6}, x_{7}\right]^{\top} \\
U_{2}=\left[I_{\text {Batt }}, V_{O C V}\right]^{\top}=\left[u_{1}, u_{2}\right]^{\top} \\
Y_{2}=\left[V_{B a t t}, S O C, P_{B a t t}\right]^{\top}=\left[y_{1}, y_{2}, y_{3}\right]^{\top} \\
\dot{x}_{1}(t)=-\frac{x_{1}}{x_{6} \cdot x_{3}}-\frac{u_{1}}{x_{3}} \\
\dot{x}_{2}(t)=-\frac{x_{2}}{x_{7} \cdot x_{4}}-\frac{u_{1}}{x_{4}} \\
y_{1}(t)=u_{2}+x_{1}+x_{2}+x_{5} \cdot u_{1} \\
y_{2}(t)=S O C_{i}-\frac{\int_{t_{0}}^{t} u_{1} d t}{Q} \\
y_{3}(t)=y_{1} \cdot u_{1}
\end{gathered}
$$

where, $R_{T S}, C_{T S}$ and $V_{C T S}$ represent the resistance, capacitance, and voltage drop in the shorter time constant RC circuit, respectively; $R_{T L}, C_{T L}$, and $R_{C T L}$ represent the resistance, capacitance, and voltage drop in the longer time constant RC circuit, respectively; $R_{S}$ is the series resistance, $V_{O C V}$ is the open circuit voltage (OCV), $Q$ is the battery capacity, $I_{\text {batt }}$ is the battery current, and $S O C_{i}$ is the initial state of charge of the battery. All these parameters are dependent on the temperature and SOC.

The battery model was validated against vehicle experimental data. Validation of SOC for US06 drive cycle is shown in Fig.12. The validation results confirm that the developed model 


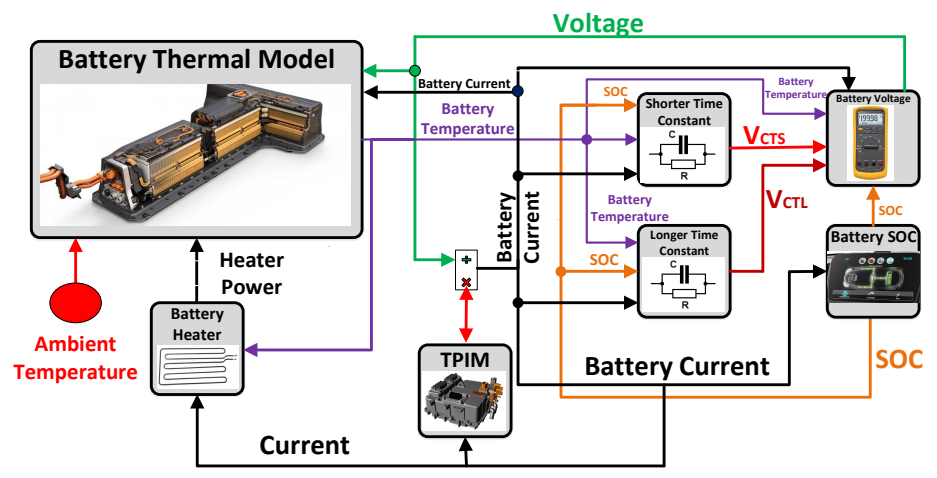

FIGURE 11: Developed battery pack model of the test vehicle. TPIM stands for traction power inverter module.

can estimate SOC with RMSE of less than $0.4 \%$.

Other methods of battery modeling such as online cell parameter estimation [45] or recursive neural networks [45] can be used to improve model accuracy and manage aging, however these methods need extensive sensor instrumentation inside the battery pack, or large operating data sets.

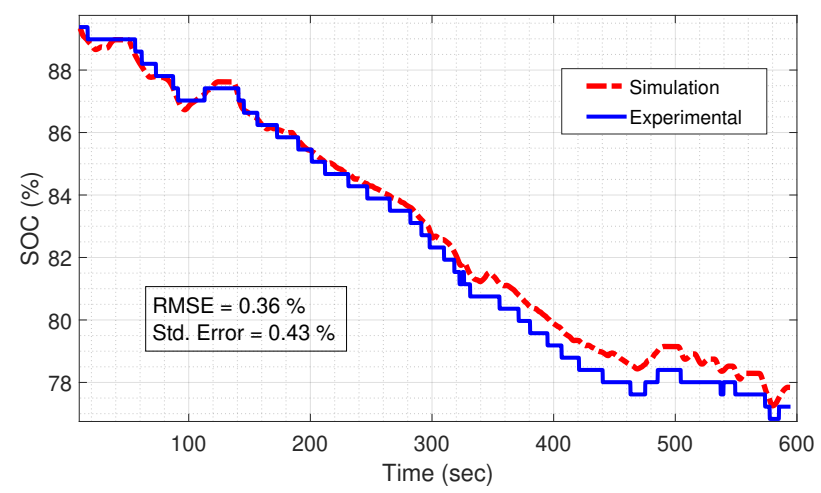

FIGURE 12: Battery model experimental validation for predicting SOC during charge depleting operation in US06 drive cycle.

\subsection{Drivetrain Model and Operating Modes}

Chevy Volt Gen II has five operating modes, mechanized using two planetary gear sets and three clutches, depending on the vehicle speed and traction torque requirements. Fig. 13 shows these five modes including $i$ ) one motor EV (1EV), ii) two motor

EV (2EV), iii) low extended-range (LER), $i v$ ) fixed gear (FG), and $v$ ) high extended-range (HER).

(a) One Motor EV (1EV)

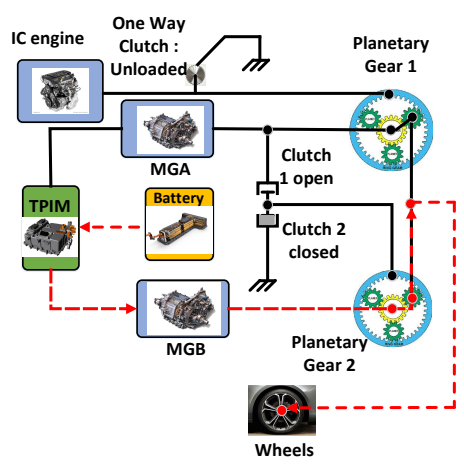

(c) Low Extended Range (LER)

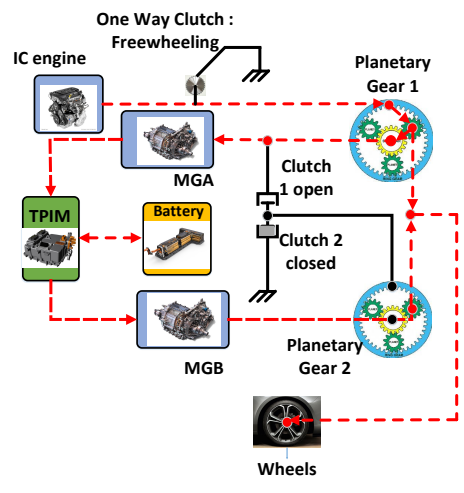

(b) Two Motor EV (2EV)

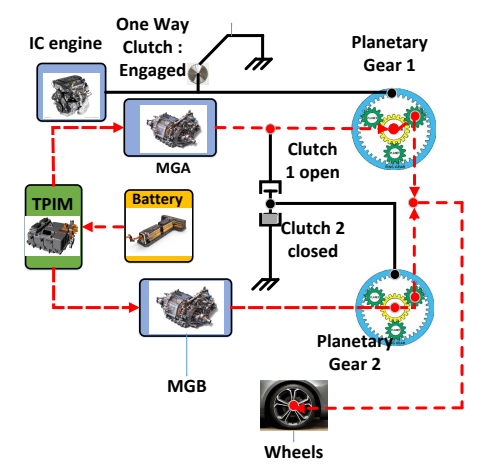

(d) Fixed Gear (FG)

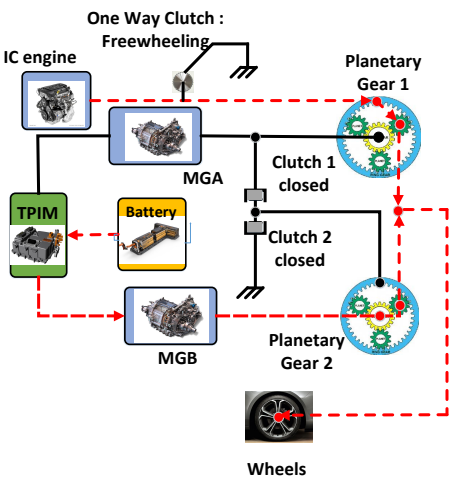

(e) High Extended Range (HER) One Way Clutch:

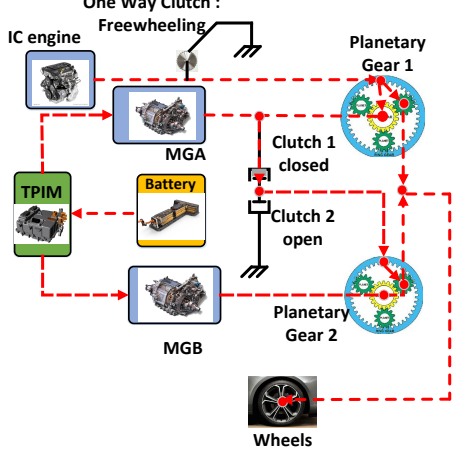

FIGURE 13: Five operating modes of the test vehicle during charge-depleting $(a, b)$ and charge-sustaining $(c, d, e)$ operation. TPIM stands for traction power inverter module. 
Fig. 13-(a) shows 1EV mode power flow in which MGB carries out propulsion and regeneration braking. Fig. 13-(b) shows 2EV mode power flow in which both MGB and MGA carry out propulsion of the vehicle. Fig. 13-(c) shows LER mode power flow in which the engine assists MGB in vehicle propulsion and a fraction of engine fuel energy is converted into electrical energy by MGA. Fig. 13-(d) shows FG mode power flow in which both engine and MGB propel the vehicle. Fig. 13-(e) shows HER mode power flow in which engine, MGA, and MGB propel the vehicle. These modes are decided by the supervisory controller based on the driver torque request, axle torque, vehicle speed, battery SOC, acceleration/ deceleration rate, current mode, and other factors. The equations to capture drivetrain dynamics for simulating drivetrain output torque and speed can be determined using the energy balance and kinematics equations. For brevity, only two sets of these equations for 2EV and HER modes are mentioned in Eq. (39) and Eq. (40).

$$
\left[\begin{array}{ccccc}
I_{\text {vehicle }} & 0 & 0 & P_{1} & P_{2} \\
0 & I_{M G A} & 0 & -S_{1} & 0 \\
0 & 0 & I_{M G B} & 0 & -S_{2} \\
P_{1} & -S_{1} & 0 & 0 & 0 \\
P_{2} & 0 & -S_{2} & 0 & 0
\end{array}\right]\left[\begin{array}{c}
\dot{\omega}_{\text {out }} \\
\dot{\omega}_{M G A} \\
\dot{\omega}_{M G B} \\
F_{1} \\
F_{2}
\end{array}\right]=\left[\begin{array}{c}
-T_{\text {load }} \\
T_{M G A} \\
T_{M G B} \\
0 \\
0
\end{array}\right]
$$

Where, $I_{M G A}$ is inertia of MGA. $F_{1}$ is internal force acting between the gears of planetary gear 1 (PG1) and, $T_{M G A}$ is torque generated by MGA. $S_{1}$ and $R_{1}$ are radii of sun and ring gear for planetary gear 1 (PG1). $\dot{\omega}_{M G A}$ is angular acceleration of MGA. In addition, $P_{1}=S_{1}+R_{1}$ and $P_{2}=S_{2}+R_{2}$.

$$
\left[\begin{array}{cccccc}
I_{\text {vehicle }} & 0 & 0 & 0 & P_{1} & P_{2} \\
0 & I_{e} & 0 & 0 & -R_{1} & 0 \\
0 & 0 & I_{M G A} & 0 & -S_{1} & -R_{2} \\
0 & 0 & 0 & I_{M G B} & 0 & -S_{2} \\
P_{1} & -R_{1} & -S_{1} & 0 & 0 & 0 \\
P_{2} & 0 & -P_{2} & 0 & 0 &
\end{array}\right]\left[\begin{array}{c}
\dot{\omega}_{\text {out }} \\
\dot{\omega}_{e} \\
\dot{\omega}_{M G A} \\
\dot{\omega}_{M G B} \\
F_{1} \\
F_{2}
\end{array}\right]=\left[\begin{array}{c}
-T_{\text {load }} \\
T_{e} \\
T_{M G A} \\
T_{M G B} \\
0 \\
0
\end{array}\right]
$$

\subsection{Mode-switching Energy Penalty}

Vehicle components require extra energy to perform mode transition. If this energy penalty information is known, intelli- gent strategies can be incorporated in the supervisory controller to minimize those energy penalties and optimize energy consumption. There is an energy penalty associated with the mode switching in the test vehicle, depending which modes are involved. For instance, for switching from $2 \mathrm{EV}$ to LER mode requires the engine to start. As explained previously in Section 3.1, depending on the engine coolant temperature and TWC temperature, fuel penalties are induced and should be considered. Fig. 6-(a) shows the mode switching penalty as a result of engine startup.

The vehicle transmission unit includes a pump, an auxiliary pump, and a transmission. The pump pressurizes transmission oil when an engine is operating; however, when the engine is not operating, the auxiliary pump coupled to the pump in parallel pressurizes the transmission oil. During mode transitions, the test data of the test vehicle's auxiliary pump showed an instant increase (i.e., spike) in auxiliary pump power consumption for a few seconds. This spike in power should be considered as part of the mode switch penalty. A data-driven auxiliary pump model is developed and validated to estimate the energy consumption by the auxiliary pump. As shown in Fig. 6-(b), the energy penalties associated with mode switching in transmission unit auxiliary pump results in energy penalties over $1 \mathrm{~kJ}$ (for FG to HER mode switch). This is because of the higher vehicle speed and tractive effort in the HER mode, which tolls the transmission unit auxiliary pump.

\section{Discussion}

The developed powertrain model from Section 3 can be used for analysis, optimization, and design of control strategies for CHEVs. Examples of the application of the powertrain model could be: $i$ ) selection of optimum vehicle operating mode (1EV, 2EV, LER, FG, HER), ii) selection of optimum speed and torque for the e-motor and the engine, and iii) design of mode-switching strategies by considering powertrain energy penalty occurrences during each mode switching. Here, these applications are briefly explained.

The powertrain operation and CHEV energy consumption highly depends on the vehicle mode of operation. Fig. 14 shows the vehicle speed and operating modes for charge-sustaining operation of the test vehicle during US06, UDDS, and HWFET 
drive cycles. It can be seen that the vehicle operates in FG and HER modes at higher speeds and use LER mode to transition to the two modes. To start the vehicle from the stationary condition, the vehicle is commanded to operate in EV1 and EV2 modes by the supervisory controller. The threshold values for deciding to operate the vehicle in different modes can be optimally selected when the transient dynamics of the vehicle is taken into account.

(a) US06

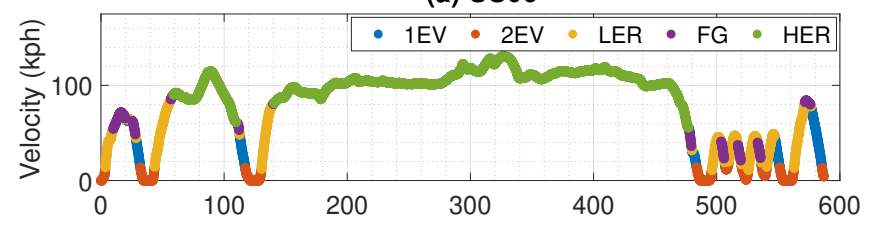

(b) UDDS

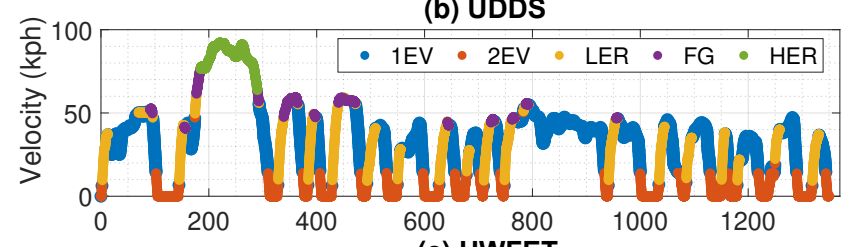

(c) HWFET

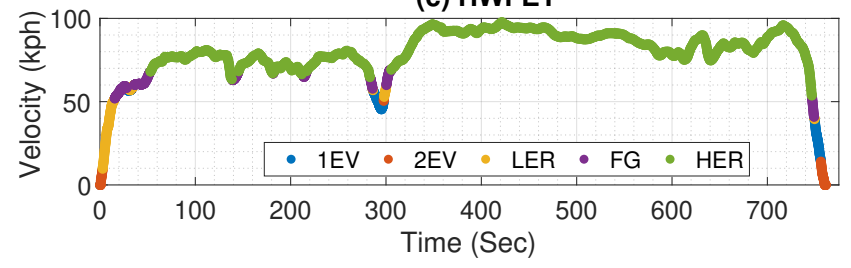

FIGURE 14: Vehicle operating modes (Fig. 13) during three US federal drive cycles.

The developed model from Section 3 is used to analyze powertrain operation during the three drive cycles in Fig. 14. The results are shown in Figures 15 to 17. The following observations can be made: $i$ ) The engine operating points for the FG mode are very well located in the efficient BSFC region; however, for the LER and HER modes, the distribution of operating points is scattered across larger BSFC region with poor efficiency values compared to the FG mode (shown in Fig. 15). The center of LER, FG, and HER point clusters is: 82 N.m and 2400 RPM for LER mode, 100 N.m and 3000 RPM for FG mode, and 80 N.m and 1900 RPM for HER mode. This is because all prime movers of the vehicle being involved at LER and HER modes for propulsion, while for the FG mode, the only operating prime mover is the engine. This results in sub-optimal engine operation in LER and HER modes at the expense of meeting other requirements for MGA and MGB, beyond just the engine BSFC efficiency. ii) As shown in the Fig. 16, the e-motors' operation in four quadrants of the speed-torque plane have distinct patterns. MGA is a smaller and less efficient e-motor compared with MGB (maximum efficiency of $94 \%$ vs $96 \%$ ) and achieves its maximum efficiency at higher speeds. During the US06 drive cycle, the MGA rarely operates at the best efficiency points and instead, operates with $80 \%$ to $91 \%$ efficiency, while MGB operates frequently in its high efficiency region and overall, operates with $86 \%$ to $96 \%$ efficiency. For US06 drive cycle, the average efficiencies of MGA and MGB are $89.1 \%$ and $92.5 \%$, respectively. iii) for quadrant two (positive torque and negative speed), MGA and MGB only operate in the LER and HER modes, respectively. The same pattern is observed for quadrant three (negative torque and speed).

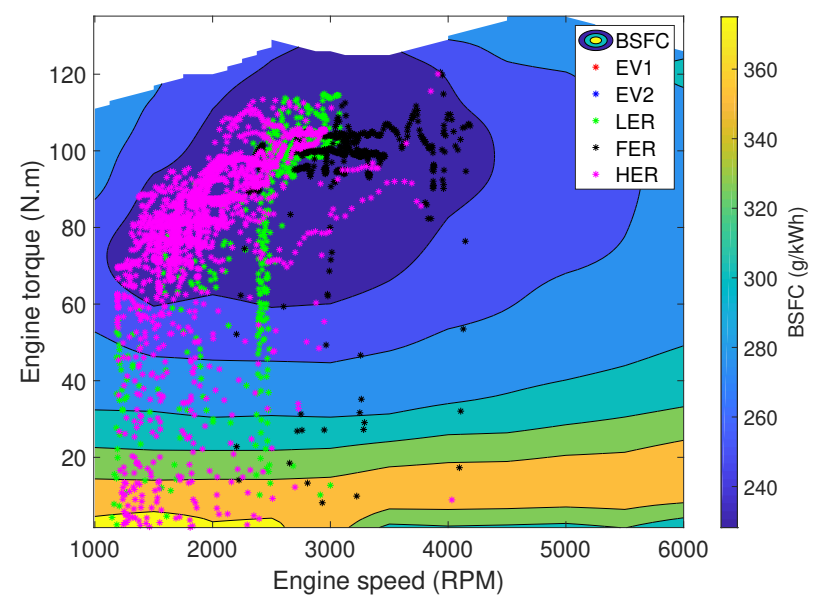

FIGURE 15: Engine operating points on the engine BSFC map along with vehicle operating modes for US06 drive cycle.

Vehicle operation in the charge depleting mode is analyzed using the developed powertrain model and part of the results is shown in Fig.17. The results indicate that: i) MGB consumes the majority of the energy in all three drive cycles. Since the UDDS cycle has frequent start-stop events and low driving speeds, MGA assists total requirements but its contribution is about $1 \%$ of the total. For the high speed drive cycles of HWFET and US06, MGA is used negligibly, too. ii) The auxiliary pump losses are much higher in the UDDS drive cycle at $8 \%$ of total 
(a)

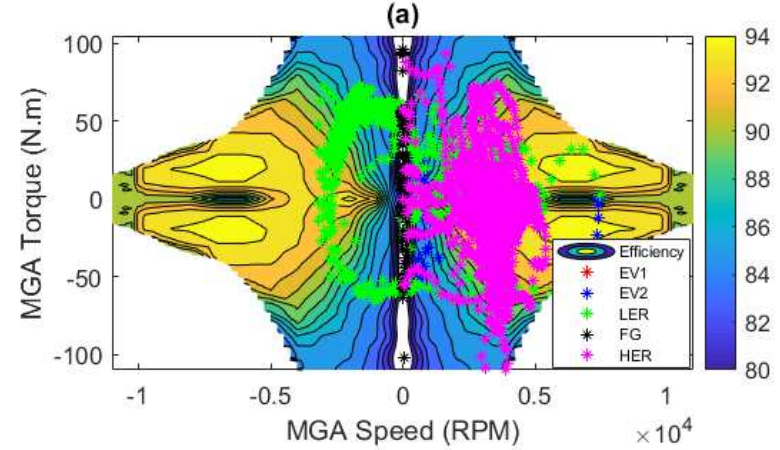

(b)

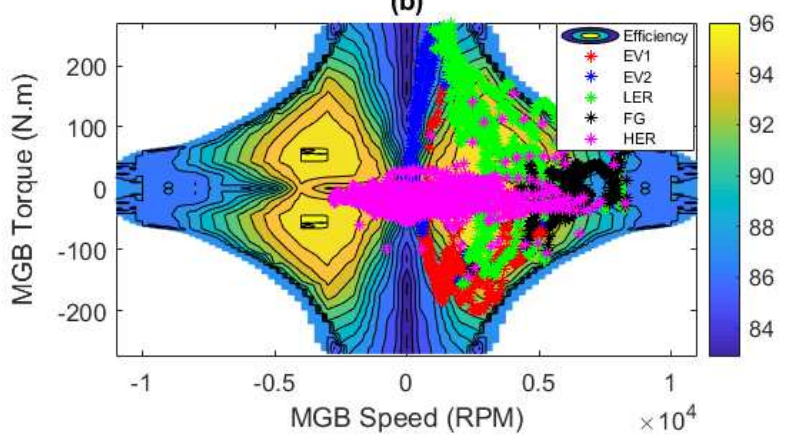

FIGURE 16: Operating points of (a) MGA and (b) MGB illustrated on emotor efficiency maps along with vehicle operating modes for US06 drive cycle.
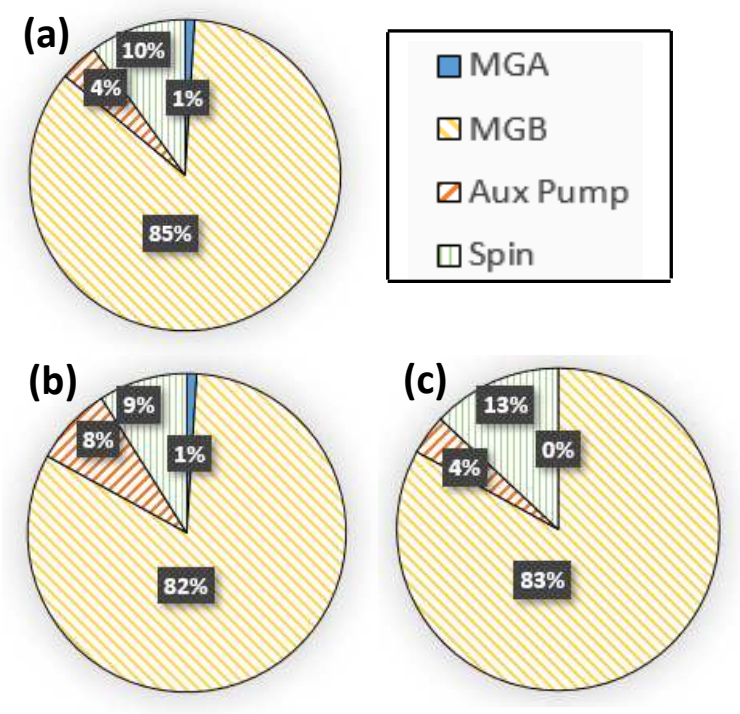

FIGURE 17: Energy distribution analysis by sub-components in chargedepleting operating mode for (a) US06, (b) UDDS, and (c) HWFET drive cycles. Note: MGA and MGB stand for motor-generator A and B, "Aux pump" stands for transmission auxiliary pump, and "Spin" stands for spinning losses. energy consumption. This value is nearly double the values for the US06 and HWFET drive cycles (4\%). Since the UDDS drive cycle has highly dynamic torque requests compared to US06 and HWFET, the pump encounters greater resistances to pump the auxiliary pump fluid and hence consumes higher energy. iii) Regarding the spin losses, the UDDS cycle has a lower spin loss contribution of 9\%, whereas the HWFET and US06 cycles are at $13 \%$ and $11 \%$. This is due to higher speeds for HWFET and US06 drive cycles which create high viscous drag on the gear surfaces and contributes to higher spin losses.

Fig. 18 shows the vehicle speed and axle torque scatter plot with data points from UDDS, US06 and HWFET drive cycles. Visually, it is clear that there are clusters of the points for each operation mode; however, these clusters are not completely separated from each other and their boundaries contain overlapping points. Given there is energy penalty for mode switching (Fig. 6), frequent mode switching should be avoided. This can happen when the vehicle is operating at axle torque- vehicle speed boundaries in Fig. 18. The developed model from Section 3 is used to determine the minimum switching time to avoid hysteresis energy penalty for mode switching (Fig. 19). The results from Fig. 19 can be directly used in CHEV supervisory controller to minimize vehicle energy consumption.

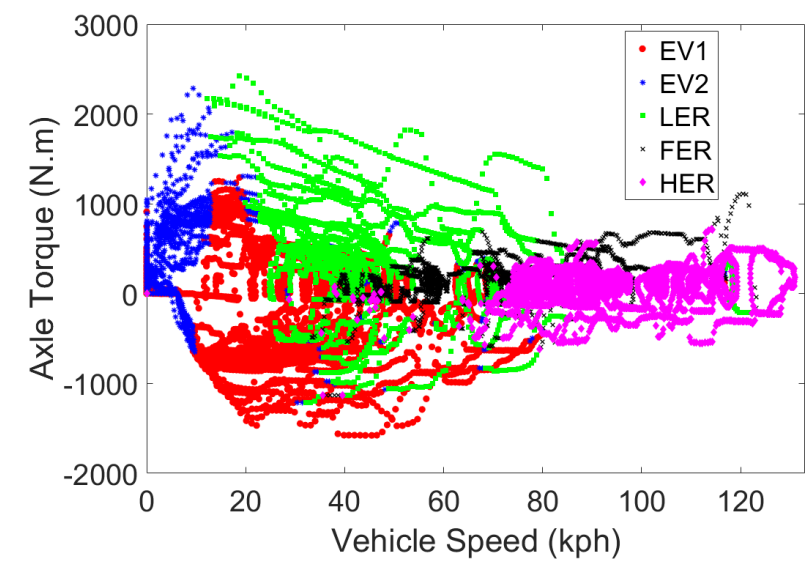

FIGURE 18: Vehicle operating points based on UDDS, US06, and HWFET drive cycles, during charge-sustaining operation.

The developed dynamic powertrain model is embedded inside a model predictive control framework to select the optimum 


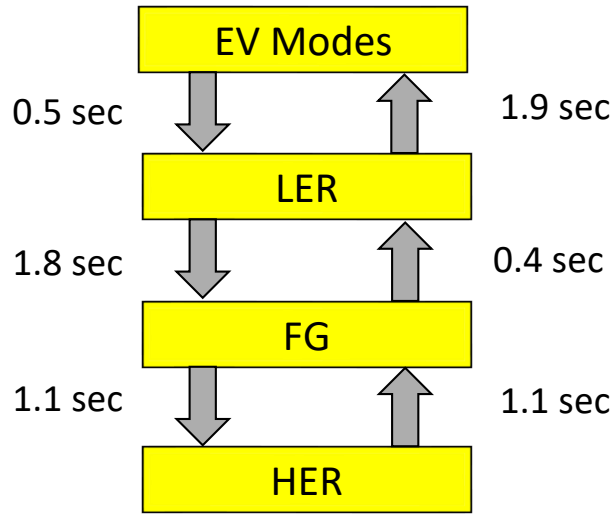

FIGURE 19: The optimized hysteresis values in acceleration and deceleration scenarios for mode-switching, using the developed powertrain model.

vehicle and powertrain operating modes by utilizing the vehicle connectivity data. Using the powertrain model from this work, the authors in [25] present a nonlinear model predictive control strategy for the same vehicle platform of this study (Chevy Volt II), to make torque-split decisions. Depending on the prediction horizon and the look-ahead information, the values of drop in the test vehicle's battery SOC during one US06 driving cycle will differ, where the 10 second prediction horizon provides the most efficient operation. The reported energy saving for a real-world drive cycle using the powertrain model is in the range of 1 to $4 \%$.

In another study [27], the authors used the powertrain model described in this paper to optimally select the vehicle operating mode in conjunction with a speed planning algorithm. The authors used an equivalent consumption minimization strategy (ECMS) to minimize the equivalent fuel cost at each operating point. The authors did not provide the energy saving percentage but in the reported optimal operation, the engine operation is constrained to the best BSFC region only. In [31], the authors utilized the powertrain model developed in this work as part of a combined motion planning and powertrain control algorithm to reduce vehicle energy consumption by avoiding wasteful driving maneuvers implemented by an automatic control and dynamic optimization (ACADO) toolkit for real-time execution. The reported energy savings range from $1.4 \%$ to $9.4 \%$ on a real-world driving cycle.

\section{Summary and Conclusions}

This paper presented the essential powertrain dynamics that are important to consider for modeling a CHEV, using the Chevy Volt gen II testbed. Dynamic powertrain models were developed and experimental validated for the powertrain sub-systems, including the engine, electric motor-generators, battery, and drivetrain. These include computationally efficient powertrain models for control of CHEVs. The developed dynamic powertrain model can predict the vehicle energy consumption with an overall prediction error of less than $5 \%$.

For the engine, startup fuel penalty terms (i.e., cold-start, catalyst light-off, and cranking fuel penalties) were considered. In addition, an engine speed-torque map was created to determine the fuel penalty for the engine transients. Furthermore, mode-switching energy penalty terms related to transmission unit auxiliary pump were quantified, helping the vehicle controller to make intelligent decisions to minimize energy penalty during mode switching. The vehicle operating modes for three U.S drive cycles were presented. The energy distribution analysis carried out in the discussion provided the share of each energy source/ sink for the three federal drive cycles which showed the MGB has a share above $80 \%$ for all three drive cycles.

The developed dynamic powertrain model can be utilized within a model-based CHEV controller to optimally select powertrain modes based on forecasted traction power needs. This paper presented the use of the developed powertrain model to avoid hysteresis during acceleration and deceleration scenarios. The results of using the developed powertrain model within CHEV controllers in our studies $[25,27,29-31]$ show the energy saving up to $9.4 \%$

\section{Acknowledgment}

This work is supported by the U.S. Department of Energy, Advanced Research Projects Agency - Energy, ARPA-e (Grant \# DE-AR0000788). Any opinions, findings and conclusions expressed in this material are those of the authors and do not necessarily reflect the views of the sponsoring institution. The authors would like to thank the General Motors (GM) company, and the MTU NEXTCAR team for their support and technical discussions. Finally, the authors would like to thank Kevin Stutenberg, Henning Lohse-Busch, and Eric Rask at Argonne National Lab- 
oratory for providing Chevy Volt II chassis dynamometer test data.

\section{REFERENCES}

[1] Sciarretta, A., and Vahidi, A. "Energy Saving Potentials of CAVs," In: Energy-Efficient Driving of Road Vehicles. Lecture Notes in Intelligent Transportation and Infrastructure. Springer. doi:030-24127-8-1.

[2] United States Energy Information Administration, "Annual Energy Outlook (2020), Transportation" Online: Accessed on October 21, 2020. URL: $\quad$ https://www.eia.gov/outlooks/aeo/pdf/ AEO202020Transportation.pdf

[3] Gao, D. W., Mi. C., and Emadi, A., "Modeling and Simulation of Electric and Hybrid Vehicles," in Proceedings of the IEEE, Vol.. 95, no. 4, pp. 729-745, April 2007, doi: 10.1109/JPROC.2006.890127.

[4] Wilcutts, M. A., and Hedrick, J. K. , "Modelbased control for automotive cold start applications", Vehicle System Dynamics, 45:5, 399-411, DOI: 10.1080/00423110701321297.

[5] Liu, J., and Peng, H. "Modeling and Control of a PowerSplit Hybrid Vehicle," in IEEE Transactions on Control Systems Technology, Vol. 16, no. 6, pp. 1242-1251, Nov. 2008, doi: 10.1109/TCST.2008.919447.

[6] Tremblay, B., and Dessaint, A. "Experimental Validation of a Battery Dynamic Model for EV Applications". World Electric Vehicle Journal Vol. 3, no. 2: 289-298. https://doi.org/10.3390/wevj3020289.

[7] AVL Advanced Simulation Technologies, "Tools and Methods for Next-Level Simulation Solutions," Online: Accessed on December 20, 2020. URL: https : //www.avl.com/documents/10138/885977/AVL + Advanced + Simulation + Technologies + Catalog.pdf .

[8] Jurkovic, S., Rahman, K., Patel, N., and Savagian. P. “ Next Generation Voltec Electric Machines; Design and Optimization for Performance and Rare-Earth Mitigation". SAE International Journal of Alternative Power, doi:10.4271/2015-01-1208, 2015.

[9] Xiong, R., Duan, Y., Cao, J., and Yu, Q., "Battery and ultracapacitor in-the-loop approach to validate a real-time power management method for an all-climate electric ve- hicle ”. Applied Energy, Vol. 217, Pages 153-165, 2018, https://doi.org/10.1016/j.apenergy.2018.02.128.

[10] J. Zhao, Y. Hu, S. Muldoon and C. Chang, "InfoRich" Eco-Driving Control Strategy for Connected and Automated Vehicles," 2019 American Control Conference (ACC), Philadelphia, PA, USA, 2019, pp. 4621-4627, doi: 10.23919/ACC.2019.8814727.

[11] Han, J., Vahidi, A., and Sciarretta, A. "Fundamentals of energy efficient driving for combustion engine and electric vehicles: An optimal control perspective ". Automatica, Vol. 103, 2019, Pages 558-572, https://doi.org/10.1016/j.automatica.2019.02.031.

[12] Shao, Y., Mohd Zulkefli, M. A., and Sun, Z. "Vehicle and Powertrain Optimization for Autonomous and Connected Vehicles". ASME. Mechanical Engineering, 139(09): S19-S23. September 2017. https://doi.org/10.1115/1.2017Sep-6.

[13] Y. Shao and Z. Sun, "Optimal Vehicle Speed and Gear Position Control for Connected and Autonomous Vehicles". 2019 American Control Conference (ACC), Philadelphia, PA, USA, 2019, pp. 545-550, doi: 10.23919/ACC.2019.8814652.

[14] Nikzadfar, K., Bakhshinezhad, N., MirMohammadSadeghi, S.A., and Taheri Ledari, H., "An Optimal Gear Shifting Strategy for Minimizing Fuel Consumption Based on Engine Optimum Operation Line," SAE Technical Paper 2019-01-5055, 2019, doi:10.4271/2019-01-5055.

[15] Oglieve, C., Mohammadpour, M., and Rahnejat, Homer. "Optimisation of the vehicle transmission and the gearshifting strategy for the minimum fuel consumption and the minimum nitrogen oxide emissions". Proceedings of the Institution of Mechanical Engineers, 2017, Part D: Journal of Automobile Engineering. 231. 095440701770298. 10.1177/0954407017702985.

[16] S. Hemmati, N. Doshi, K. Surresh, M. Shahbakhti, "Essential Dynamics for developing models for control of connected and automated electrified vehicles: PART B - thermal management and vehicle dynamics", To be submitted to Journal of Dynamics Systems, Measurement, and Control.

[17] Lu, C., Dong, J., and Hu, L. "Energy-Efficient Adaptive 
Cruise Control for Electric Connected and Autonomous Vehicles," in IEEE Intelligent Transportation Systems Magazine, Vol. 11, no. 3, pp. 42-55, Fall 2019, doi: 10.1109/MITS.2019.2919556.

[18] Wu, F., Yu, Y., Wang, J., Liu, Z., Li, J., and Nie, J., "Predictive energy-saving optimization based on nonlinear model predictive control for cooperative connected vehicles platoon with V2V communication," Energy, Elsevier, Vol. 189(C). 2019. https://doi.org/10.1016/j.energy.2019.116120.

[19] Batra, M., McPhee, J., and Azad, N. L. (2019) "Realtime model predictive control of connected electric vehicles", Vehicle System Dynamics, 57:11, 1720-1743, DOI: 10.1080/00423114.2018.1552004.

[20] Batra, M., Maitland, A., McPhee, J., and Azad, N. L. "NonLinear Model Predictive Anti-Jerk Cruise Control for Electric Vehicles with Slip-Based Constraints," 2018 Annual American Control Conference (ACC), Milwaukee, WI, 2018, pp. 3915-3920, doi: 10.23919/ACC.2018.8431389.

[21] Yi, Z., and Shirk, M. "Data-driven optimal charging decision making for connected and automated electric vehicles: A personal usage scenario." Transportation Research Part C-emerging Technologies, Vol. 86, 2018, Pages 37-58, https://doi.org/10.1016/j.trc.2017.10.014.

[22] Gupta, S., Rajakumar Deshpande, S., Tufano, D., and Canova, M., "Estimation of Fuel Economy on Real-World Routes for Next-Generation Connected and Automated Hybrid Powertrains," SAE Technical Paper 2020-01-0593, 2020, doi:10.4271/2020-01-0593.

[23] Ma, G., Ghasemi, M., and Song, X., "Integrated Powertrain Energy Management and Vehicle Coordination for Multiple Connected Hybrid Electric Vehicles," in IEEE Transactions on Vehicular Technology, Vol. 67, No. 4, pp. 2893-2899, April 2018, doi: 10.1109/TVT.2017.2780268.

[24] HomChaudhuri, B., Lin, R., and Pisu, R. "Hierarchical control strategies for energy management of connected hybrid electric vehicles in urban roads, Transportation Research Part C: Emerging Technologies, Vol. 62, 2016, Pages 7086, https://doi.org/10.1016/j.trc.2015.11.013.

[25] Oncken, J., and Chen, B. (2020). "Real-Time Model Predictive Powertrain Control for a Connected Plug-In Hy- brid Electric Vehicle", in IEEE Transactions on Vehicular Technology, Vol. 69, no. 8, pp. 8420-8432, Aug. 2020, doi: 10.1109/TVT.2020.3000471.

[26] Zhao, L., Mahbub. A. M., and Malikopoulos, A. A. "Optimal Vehicle Dynamics and Powertrain Control for Connected and Automated Vehicles," 2019 IEEE Conference on Control Technology and Applications (CCTA), Hong Kong, China, 2019, pp. 33-38, doi: 10.1109/CCTA.2019.8920531.

[27] Wang, H., Sacheva, K., Tripp, J., Chen, B., Robinette, D., and Shahbakhti, M. "Optimal Map-Based Mode Selection and Powertrain Control for a Multi-Mode Plug-in Hybrid Electric Vehicle," 2018 14th IEEE/ASME International Conference on Mechatronic and Embedded Systems and Applications (MESA), Oulu, 2018, pp. 1-6, doi: 10.1109/MESA.2018.8449157.

[28] Chau, C., Elbassioni, K., and Tseng, C., "Drive Mode Optimization and Path Planning for Plug-In Hybrid Electric Vehicles," in IEEE Transactions on Intelligent Transportation Systems, Vol. 18, no. 12, pp. 3421-3432, Dec. 2017, doi: 10.1109/TITS.2017.2691606.

[29] Doshi, N., Hanover, D., Hemmati, S., Morgan, C., Shahbakhti, M., "Modeling of Thermal Dynamics of a Connected Hybrid Electric Vehicle for Integrated HVAC and Powertrain Optimal Operation," Proceedings of the ASME 2019 Dynamic Systems and Control Conference. Vol. 2, Park City, Utah, USA. October 8-11, 2019. V002T23A005. ASME. https://doi.org/10.1115/DSCC2019-9223.

[30] S. Hemmati, N. Doshi, D. Hanover, C. Morgan, M. Shahbakhti, "Integrated cabin heating and powertrain thermal energy management for a connected hybrid electric vehicle", , Applied Energy, Volume 283, 2021, 116353, ISSN 0306-2619, https://doi.org/10.1016/j.apenergy.2020.116353.

[31] Bhat, P. K. Oncken, J., Yadav, R., Chen, B., Shahbakhti, M., and Robinette, D. 2019, "Generation of Optimal Velocity Trajectory for Real-Time Predictive Control of a MultiMode PHEV”2019 IEEE 90th Vehicular Technology Conference (VTC2019-Fall), Honolulu, HI, USA, 2019, pp. 15, doi: 10.1109/VTCFall.2019.8891569.

[32] Hendricks, E., and Sorenson, S. C. "Mean Value Modelling 
of Spark Ignition Engines”. SAE Technical Paper Series, No. 900616, 10.4271/980784, 1998.

[33] HEYWOOD, J., "Internal Combustion Engine Fundamentals”. MCGRAW-HILL EDUCATION, 2018.

[34] Rajamani, R. "Mean Value Modeling of SI and Diesel Engines", Book chapter, Vehicle Dynamics and Control, pages 257-285,Springer US doi:10.1007/0-387-28823-6-9.

[35] Xiong, R., He H., Sun, F., and Zhao K., "Online Estimation of Peak Power Capability of Li-ion Batteries in Electric Vehicles by a Hardware- in-Loop Approach". MDPI, Energies, 2012, doi:10.3390/en5051455.

[36] K. B. Wipke, M. R. Cuddy and S. D. Burch, "ADVISOR 2.1: a user-friendly advanced powertrain simulation using a combined backward/forward approach," in IEEE Transactions on Vehicular Technology, Vol. 48, no. 6, pp. 17511761, Nov. 1999, doi: 10.1109/25.806767.

[37] "PSAT Documentation," Online: Accessed on May 2021. URL:http://www.transportation.anl.gov/software/PSAT

[38] C. C. Chan, "The State of the Art of Electric, Hybrid, and Fuel Cell Vehicles," in Proceedings of the IEEE, vol. 95, no. 4, pp. 704-718, April 2007, doi: 10.1109/JPROC.2007.892489.

[39] T. Markel and K. Wipke, "Modeling grid-connected hybrid electric vehicles using ADVISOR," Sixteenth Annual Battery Conference on Applications and Advances. Proceedings of the Conference (Cat. No.01TH8533), 2001, pp. 2329, doi: 10.1109/BCAA.2001.905095.

[40] Kim, N., Duoba, M., Kim, N., and Rousseau, A., "Validating Volt PHEV Model with Dynamometer Test Data Using Autonomie," SAE Int. J. Passeng. Cars - Mech. Syst. 6(2):985-992, 2013, https://doi.org/10.4271/2013-01-1458.

[41] Conlon, B. M., Blohm, T., Harpster, M., Holmes, A., Palardy, M., Tarnowsky, S., and Zhou, L. "The Next Generation "Voltec" Extended Range EV Propulsion System," SAE Int. J. Alt. Power, 0.4271/2015-01-1152, 2015.

[42] Knauff, M., McLaughlin, J., Dafis, C., Niebur, D., Singh, P., and Kwatny, P., "Simulink Model of a Lithium-Ion Battery for the Hybrid Power System Testbed," Electric Ship Technologies Symposium, 2007. ESTS '07, June 2007, IEEE. DOI:10.1109/ESTS.2007.372120.

[43] Roberts, A., Brooks, R., and Shipway, P. "Internal com- bustion engine cold-start efficiency: A review of the problem, causes and potential solutions". Energy Conversion and Management, Vol. 82, June 2014, Pages 327-350. doi:101016/jenconman201403002

[44] Park, S., Zhang, D., and Moura, S., "Hybrid Electrochemical Modeling with Recurrent Neural Networks for Li-ion Batteries," 2017 American Control Conference (ACC), Seattle, WA, 2017, pp. 3777-3782, doi: 10.23919/ACC.2017.7963533.

[45] Gima, Z. T., Kato, D., Klein, R., and Moura, S. J. "Analysis of Online Parameter Estimation for Electrochemical Li-ion Battery Models via Reduced Sensitivity Equations," 2020 American Control Conference (ACC), Denver, CO, USA, 2020, pp. 373-378, doi: 10.23919/ACC45564.2020.9147260. 